This item was submitted to Loughborough's Research Repository by the author.

Items in Figshare are protected by copyright, with all rights reserved, unless otherwise indicated.

\title{
Using the evidence: a comparison of Civil and Building lecturers and students' approach to the literature review
}

PLEASE CITE THE PUBLISHED VERSION

http://dx.doi.org/10.1061/(ASCE)EI.1943-5541.0000077

PUBLISHER

(C) American Society of Civil Engineers (ACSE)

VERSION

AM (Accepted Manuscript)

LICENCE

CC BY-NC-ND 4.0

\section{REPOSITORY RECORD}

Gadd, Elizabeth A., Andrew N. Baldwin, Michael Norris, and Sharon Reid. 2019. "Using the Evidence: A Comparison of Civil and Building Lecturers and Students' Approach to the Literature Review". figshare. https://hdl.handle.net/2134/8222. 
This item was submitted to Loughborough's Institutional Repository (https://dspace.lboro.ac.uk/) by the author and is made available under the following Creative Commons Licence conditions.

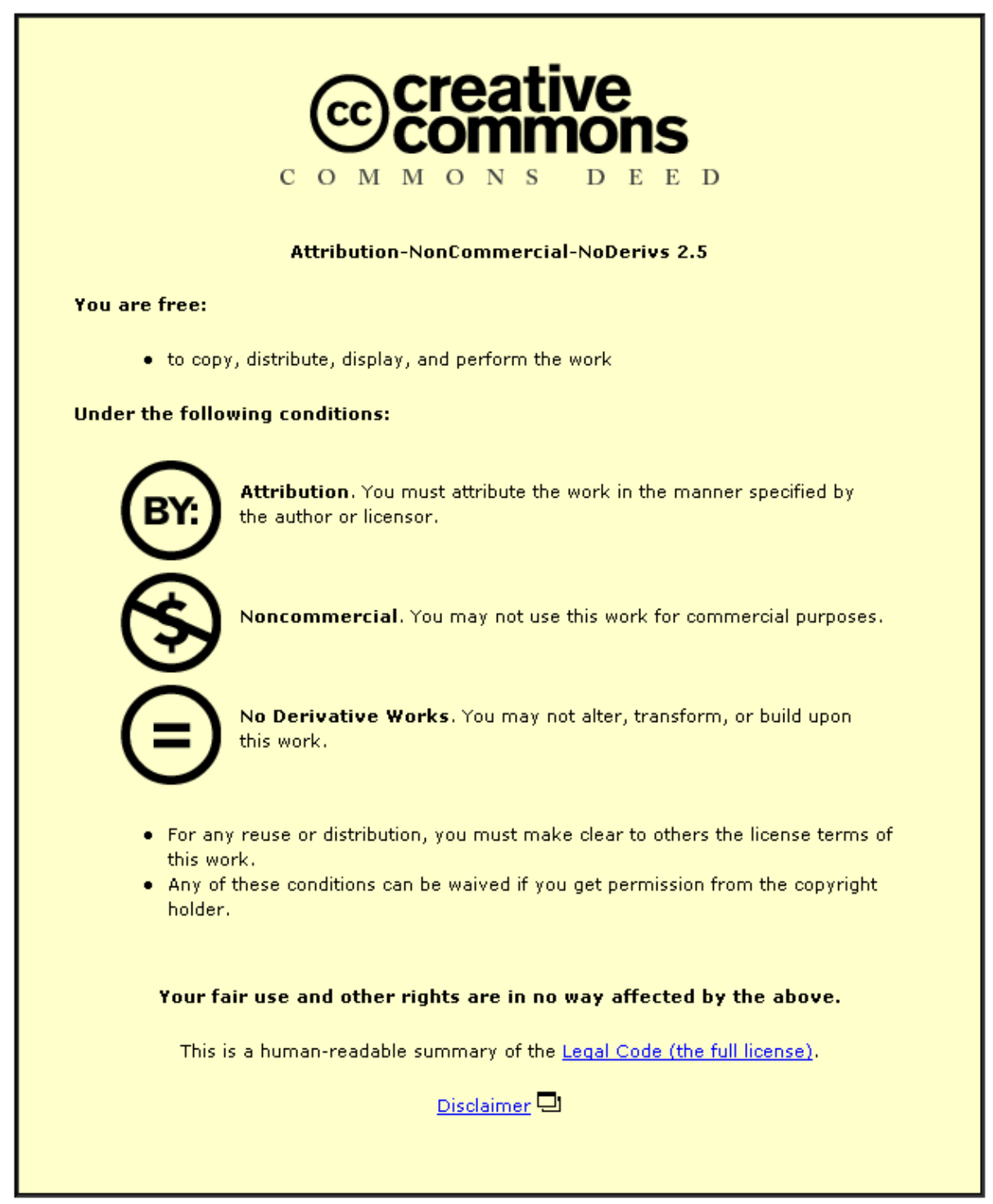

For the full text of this licence, please go to: http://creativecommons.org/licenses/by-nc-nd/2.5/ 
Using the evidence: a comparison of Civil \& Building lecturers and students' approach to the literature review.

Elizabeth Gadd ${ }^{1}$, Andrew Baldwin ${ }^{2,}$ Michael Norris ${ }^{3}$ and Sharon Reid ${ }^{4}$

${ }^{1}$ Academic Services Manager, Engineering, University Library Email:

E.A.Gadd@lboro.ac.uk

${ }^{2}$ Professor of Construction Management, Department of Civil and Building Engineering Email: A.N.Baldwin@lboro.ac.uk

${ }^{3}$ Research Associate, Department of Information Science Email: M.Norris@lboro.ac.uk

${ }^{4}$ Academic Librarian, University Library Email: S.D.Reid@lboro.ac.uk All at Loughborough University, Loughborough, Leicestershire, LE11 3TU, UK.

\section{Abstract}

Lecturers and students in the Civil \& Building Engineering Department at Loughborough University were surveyed to gain an understanding of how they expected the literature review element of Final Year Projects to be undertaken. The results showed a disparity in the number and type of resources expected to be used; in the problems they anticipated when undertaking a literature review; and in the confidence levels students had in the use of information tools. Recommendations are made to improve the teaching of the literature review.

Introduction: the New Review Project 
The New review project was a programme of work supported by the UK Centre for Education and the Built Environment (CEBE) and carried out by the Department of Civil and Building Engineering and the Pilkington Library, at Loughborough University in 2008-9. All final year Civil and Building Engineering students at Loughborough are required to complete a major piece of project work which necessitates discovering, evaluating and reviewing the literature on their chosen topic: "a literature review". The overall aim of this project was to better understand how students conduct research for their literature review, and investigate how students' performance, in this process, may be improved. The Civil \& Building Department at Loughborough runs seven undergraduate degree programmes in Civil Engineering, Commercial Management and Quantity Surveying, Construction Engineering Management, Architectural Engineering and Design Management , and Transport Management disciplines. Courses run from three to five years with optional industrial placements and can result in BEng, BSc, of MEng degrees. All programmes require the completion of a Final Year Project or Dissertation necessitating a literature review and original primary research. Projects should not exceed about 80 A4 pages in length.

At the start of the research programme the views of academic lecturers and students from the Civil and Building Engineering Department were sought, by survey, on a number of issues related to the literature review process. This paper gives the results and a brief comparative analysis of the lecturer and student surveys where very similar or identical questions were asked of both groups. 


\section{Methods}

Lecturers (the equivalent of US Faculty) were surveyed by questionnaire on a range of issues around the literature reviews written by the students they supervised for their final year projects. In all 28 lecturers' responses were received giving an overall response rate of about fifty percent. In a comparable process 54 final year students from seven different programmes responded to a similar questionnaire. Amongst these students, 8 were female and 45 male; one student did not give their gender. Whilst we did not ask which programme the students belonged to for fear it may impact on the anonymity of the survey, we did ask whether their project was a labbased or experimental project, of which 11 (20\%) said it was, 40 said not, and three did not respond. Of the questions asked of both lecturers and students seven were sufficiently similar to allow comparison. Where necessary however, questions that were asked exclusively of either lecturers or students are included to aid understanding, otherwise the seven questions common to both groups of respondents are featured in the analysis. It should be made explicit that the data upon which this paper is based represents the perceptions of students and staff in relation to the literature review. An objective analysis of the reference lists from Civil and Building Engineering students was also performed as part of this project and is the subject of another paper (Gadd, Baldwin \& Norris, 2010).

\section{Information seeking behaviour of engineering students: a brief review of the}

\section{literature}

The information seeking behaviour of civil engineering students - i.e. how they go about searching for and evaluating information (see Wilson 1999 and Case 2002) is probably not that dissimilar from most other engineering students. There is a body of 
work which does report on the information seeking behaviour of student engineers in general and a much larger one, from the mid 1960's onward, for those who progress to work in the many different engineering professions (Fidel \& Green 2004: Tenopir \& King 2004:Hertzum \& Pejtersen 2000). An argument may follow that what is learned or understood in higher education, in terms of information seeking behaviour, can influence the professional lives of engineers and how they seek the information they need for their work (Kwasitsu 2003).

Using a questionnaire Ercegovac (2009) sought to gauge how aware second year computer science and computer engineering students were of the information sources that were available to them through their library. Asked to identify how they would find a particular paper which appeared in the journal Transactions in Graphics $51 \%$ answered correctly, the remainder either did not know or answered incorrectly. When asked to rank the sources they would use to find the journal paper students selected Google and Google Scholar and the web as their top choices followed by a tail of ten other sources. Of the students, $82.8 \%(58)$ of them could not identify the university's online catalogue. When asked to identify the first best sources they would use to give a critical review of the literature for a topic they were unfamiliar with, students choose search engines and community based e-resources such as Wikipedia first. This was followed by books, articles in magazines and journals, technical reports and peer reviewed encyclopaedias. The journal Computing Reviews, the leading online review service for computing was placed as seventh best choice.

Chu \& Law (2007) examined the search expertise of 12 postgraduate research students, six of whom were studying engineering and the other six were studying education. The students were at the start of their studies and were expected to be 
involved in the review of the literature. The information seeking skills of the two groups were monitored over a period of five meetings with a clear recognition that being computer literate does not necessarily equate to being information literate. The authors were concerned with identifying the students' perception of the importance of searching skills and how these skills developed as they progressed through their studies. The study showed that research students did not know how to use certain searching techniques, even when they claimed they were familiar with the process. For example subject searches in the online catalogue were generally unsuccessful as students did not understand the use of controlled vocabularies.

There were differences in the search strategies adopted by the two groups, the engineers tended to use simpler keyword strategies as their information needs were viewed as being more specific than those in education. The research showed that the engineering students were able to get the results they needed adopting this simpler keyword strategy, although they did use Boolean operators this was much less frequent than the education students. Over the period of the five meetings perceptions changed for the students, the authors suggest, that an "association can thus be established between the students' familiarity with information searching skills and their perceived importance of these skills" and that "It is clear that an increase in students' familiarity with various information searching skills contributes significantly to the development of students' information searching expertise" (Chu \& Law 2007, p.312).

In a similar approach, researchers in Ireland compared the information seeking behaviour of engineering and law students (Kerins, Madden \& Fulton 2004). The authors choose 14 final year engineering students (electronic, mechanical and manufacturing) as they were involved in completing a final year undergraduate 
project and would use, they felt, the information seeking skills they had acquired through their earlier work. Accessibility was a key issue for these students in their selection of an information source as was ease and speed of use. Inevitably it seems this led students to use the Internet as a primary source of information with which to define their information need rather than building a detailed knowledge of their subject (Kerins, Madden \& Fulton 2004). Although it is worth noting that some students who thought the Internet the most useful source of information often felt overwhelmed by the volume of the information it could provide and the authenticity of some of the material might be questionable. Students in this position often used more traditional library resources such as books, reports and journals to verify information found on the Internet. But very few students seemed to link online resources to the library and often used online databases for finding non-technical information such as business modules although some students did recognise and value electronic resources offered by the library.

The research by Kerins, Madden \& Fulton (2004) also noted that engineering students used a variety of library resources but did not always look to the use the library first in their search information. It was suggested this happens part way through their information searching and that librarians were viewed as functionary intermediaries in this process rather than as primary sources of information and expertise. Students talked to other students, notably when doing their coursework but also they consulted their lecturers who in turn encouraged them to consult engineers in the profession. This characteristic of practising engineers to use other individuals and personal contacts as information channels appears to be embedded in the formative years of their higher education. The practice also highlights the importance of the influence that lecturers potentially have over the information 
seeking skills of their students. Kerins, Madden \& Fulton (2004) suggest that lecturers should be part of the educative process in terms of being competent and able information seekers, the corollary of which is that they should, if necessary, have access to training and routine updates on new resources acquired by the library.

Barker, Cook and Whang (n.d.) found that $47 \%$ of the engineering students at the University of Washington (from a sample of 260 survey respondents) at different stages in their education used the Internet because it was quick and easy to use. Their second choice was to consult academics and joint third was their fellow students or to use a research database. The progression to using databases and reliable sources of information was correlated with how far students had progressed in their studies with first year students being heavily reliant on the Internet. The use of the library collections and librarians was 'dismally low for all groups'. The researchers were able to breakdown their results by gender and found that:

Quickness was the most important factor for both groups in choosing an information resource. Women were more likely than men to choose a source that they considered to be reliable as their first choice, and men were more likely than women to choose a convenient source first. Women were much more likely than men to choose a source that they could interact with in person or on the phone, and men were more likely to prefer an anonymous source (Barker, Cook and Whang n.d.).

Ease and accessibility is a key issue for engineers in their search information. Fidel and Green (2004) interviewed 32 practising engineers to assess the factors that affected their choice of information sources. They found that ease of access was the most important factor but that the concept of accessibility varied depending on the 
questions the engineers sought to answer and the appropriateness of the source that they thought would help them. Information sources were selected by balancing a range of factors including the right format, the right level of detail and how much the information source could deliver in one place against the time spent accessing it. When using human information sources familiarity was the key deciding factor on who to approach.

Kwasitsu (2003) takes an interesting approach. She suggests that work roles and academic qualifications significantly influence the information seeking behaviour of engineers who worked in a microchip manufacturing company. Examining engineers from different parts of the business the research tended to show that those with higher degrees were more likely to use the corporate library and depend on conferences as sources of information. Again the research reinforced the fact that accessibility and availability were very important in source selection. Two thirds of those surveyed indicated that personal contacts were highly important sources of information and $60 \%$ rated their personal memory and personal files similarly so. Those, however, with higher degrees showed less inclination though to rely on personal contacts and their personal files but rather to rely on experience they had gained in their education and were "... not only aware of library resources but had acquired a culture of finding and using reliable, published information" (Kwasitsu 2003, p.467).

Baer and Li (2009) used a survey to establish the information use patterns of undergraduate and postgraduate students and their faculty members at Georgia Institute of Technology. Two schools of engineering were surveyed, civil and environmental and mechanical. Over $60 \%$ of undergraduate students agreed or strongly agreed that Google was sufficient for their information needs with consulting 
their colleagues the next most popular choice at $27 \%$. This result changed markedly for graduate students who thought that Google, on the same basis, only met their research needs $22 \%$ of the time and for faculty members this was only $7 \%$. When undergraduates were asked to rank the top five databases from a given list in their field they chose Google Scholar, many of them had no knowledge of the standard subscription databases such as ASCE's Civil Engineering Abstracts or Thomson Reuter's Web of Science. This changed little with fourth year students similarly choosing Google Scholar as their top database with $66 \%$ of them having no knowledge of the major engineering database, Elsevier's Compendex. For graduate engineers the Web of Science and Compendex were the two most popular first choices.

Students at the Institute were also asked what sort of library resource training they preferred. The majority preferred online tutorials first with one-on-one consultation coming second, closely followed by information booklets. When asked how they would seek research help from the from the library, students overwhelmingly, ( $87 \%$ undergraduates \& $75 \%$ graduates) had a preference to go to an information service desk for help. However, $19 \%$ of the undergraduates and $17 \%$ of graduates did not answer the question at all.

\section{Survey results and analysis}

Here at Loughborough lecturers were asked how important they believed a good literature review was to obtaining an 'excellent' dissertation or project and similarly students were asked, compared to the whole dissertation or project, how important they thought the literature review element was. Figure 1 shows the comparable results. 
Figure 1. The importance of the literature review to lecturers and students

Three lecturers (10\%) indicated that the literature review was very unimportant (although it is believed they may have mis-read the question), 18\% thought it important and the remaining $71 \%$ thought it very important. Five (9\%) of the students thought the importance of the literature review either very unimportant or unimportant. Three of this five had already stated that their project was either a laboratory-based or experimental project, which may explain why they felt the literature review was less important. The remaining $90 \%$ of students divided into $25 \%$ who thought it important and 65\% who thought it very important.

A question asked only of lecturers was how they rated the general standard of students' literature reviews performed by previous students in the Department. Their responses shown in Table 1 indicate that only 43\% of lecturers believe their students do an adequate (good) job. A further $43 \%$ perceived the general standard of final year students' literature reviews to be either poor or very poor.

\section{Table 1 Quality of literature reviews}

This was followed by a question that asked both lecturers and students what they believed the main purpose of the students' literature review was. Both lecturers and students were offered a list of five options and asked to tick as many as applied. In slightly different wording students were asked what the main purpose of their literature review was. The combined results are show in Figure 2. Percentages represent the respondents who selected a particular category. So for example 25 lecturers (89\%) selected the option 'To review the most relevant and significant research on your topic'. 
Figure 2. Main purpose of the literature review

As would be expected perhaps, the highest response (nearly 90\%) highlighted the fact that most lecturers believed that the main purpose of the literature review was to review the most relevant and significant research on their topic. Of almost equal importance (82\%) to the respondents was the need for students to demonstrate their familiarity with what is already known about their research topic. Student responses were not that dissimilar to those of lecturers with $91 \%$ of them agreeing on the main purpose of the literature review. Like lecturers, students also ranked second at $69 \%$ the importance of being able to demonstrate in their literature review familiarity with the research topic.

When lecturers were asked to specify what other purposes the literature review had, there were a variety of responses, including: 'To set their work and findings in context', 'to identify suitable method for their research', 'to develop appropriate writing style', 'to learn and understand the topic is most important!!', 'to be able to critique previous work', 'to obtain current knowledge in relation to the research topic they have chosen', 'to learn how to undertake investigating and write up the results

of their research' and 'to demonstrate that a student can assess that information and make decisions regarding, for example, its relevance to the topic'. There was just one response from the students and this was related to the 'production of a timeline of the background/history" of their topic.

\section{Sources of information}

Lecturers were asked what sources students should use in their literature review and students were asked what they to use. In this context, 'sources of information' refers 
to the different types of information discovery tools (databases, search engines, library tools and so on), available to identify and locate relevant articles, documents and information. Both lecturers and students were given a list to choose from. Figure 3 shows the responses from them both.

Figure 3. Sources of information for the literature review

Over $90 \%$ of lecturers expected students to use electronic journals in their literature review with just under $90 \%$ of them citing the library catalogue as a source students should also be using. Students were in close agreement with lecturers, but some differences were noticeable in the use of the internet, industrial sponsors and other students where students had a greater propensity to cite these as useful sources of information. Other resources identified included the use of Google Scholar, specific printed or electronic books, and industry or academic experts. One lecturer specified that the books and publications should be from external sources.

Anticipated problems and currency of reviews

Question 7 of the questionnaire asked what problems lecturers anticipated students might have when searching for information. This question elicited a range of free-text comments from 25 respondents with the majority citing a series of common problems. The main themes to emerge are given in Table 3.

Table 2. Problems that lecturers thought students may have in their search for information

The problem of finding relevant information was most frequently anticipated (25\%). This included knowing what and where to look for information, the potential to rely too heavily on web resources and insufficient knowledge and understanding of the 
variety of information available. Having a poor search strategy was mentioned by $21 \%$ of respondents with uncertainty and lack of knowledge about the use of keywords of particular concern to a number of respondents. Also high on the list (18\% of responses) was the student's inexperience in and lack of understanding of how to analyse information and determine its relevancy. Comments included 'knowing how to synthesise', 'lack of a suitable plan against which to determine if the information found is relevant' and 'filtering 'good' information from 'poor". Interestingly, a lack of initial guidance was mentioned by three respondents with one noting significantly that 'they [students] have not been taught how to do a lit review!' Forty-two students (77\%) gave free-text answers to the question 'What problems do you anticipate when searching for information for your project/dissertation?' Eight main themes emerged; these are given in the Table 4.

Table 3. Problems that students anticipated they might have in performing their literature review

The concern cited by the largest number of respondents was that of finding specific information. This was either because their topic was quite new ('Not too much about using rubber as a fill material - relatively new'), or because of the difficulties of finding certain types of information ('Gaining access to certain Government literature'). Related to this was a concern about finding relevant information. Comments such as 'Irrelevant information, especially on the internet' were made by $13 \%$ of the respondents. Six (11\%) highlighted the opposite problem of finding 'too much information' and how to manage it, this was also mentioned by three lecturers as 'information overload'. Five (9\%) mentioned the issue of 'Obtaining papers once 
[they] had found the reference'. Three (6\%) cited the problem of currency of the material.

Some problems were mentioned only by either lecturers or students. Twenty-one per cent of lecturers mentioned the likelihood of students having a poor search strategy and perhaps not surprisingly these lecturers were amongst some of the same lecturers that thought students would also have difficulty finding relevant information. Similarly some students and lecturers thought that students might have difficulty having the right study skills. Both groups mentioned time management as one particular issue.

Lecturers were asked whether they expected students to keep reviewing relevant literature throughout the project period and likewise students were asked if they expected to do the same, which they did, with 24 lecturers (85\%) and all but one student (98\%) agreeing. A number made additional comments. Two respondents qualified their affirmative responses by stating that they only expected students to do so 'a little' or in 'a limited way'. However, one respondent expressed the opinion that it was 'vital' in 'fast changing areas' whilst another commented that he/she would expect students to do so 'but they don't'. Of those who didn't expect students to keep reviewing the literature, one commented that it was in fact 'desirable but not practical' whilst another qualified his response by stating that the students should 'review from November to February'. 
Lecturers were asked how many information resources they expected students to search as part of their literature review and in turn students were asked how many they expected to search. In this context, 'information resources' refers to the different resource discovery tools such as databases, search engines and so on, that lecturers expect their students to use to identify and locate relevant articles, documents and information. The responses from both sets of respondents are shown in Figure 4.

Figure 4. Number of information resources expected for the literature review

Of the 21 lecturers responses, over $50 \%$ of respondents (11) expected their students to search between 6-10 resources. However, in a marked contrast almost 54\% of students (29) thought they would search over 15 resources, a noticeable difference in perceptions. One lecturers respondent made an additional point, stating:

I don't think a number should be specified, numbers should reflect the specific subject - what amount of information is available, and more importantly, what is relevant to their project? If numbers are advised students will tend to aim for that number and then once reached, feel they have achieved what is expected.

In a another companion question lecturers were asked how many sources they expected students to read as part of their literature review and students were asked how many they expected to read. In this context, 'number of sources' refers to the actual number of journal articles, books, data sources, reports and web sites that the students were expected to read, evaluate and write about as part of their literature review. Figure 5 gives the results.

Figure 5. Number of sources expected to be read for the literature review 
Of the 23 lecturers' responses, 43\% (10 respondents) expected their students to read between 21 and 30 sources of information. Apart from one lecturer who expected between 1 and 10 sources to be read, the rest were evenly split between 11-20 and over 30 sources (6 respondents each). Apart from one student who expected to read between 1-10 sources the remaining students were fairly evenly split between the different ranges of sources they expected to read.

\section{Perceptions of information handling and use}

Students were asked to select from one of three confidence levels (not confident, confident or very confident) to rate how confident they felt about 17 different aspects of the information search process. Lecturers were asked to rate how confident they felt their students were on 11 of these aspects. Tables 5 through 9 present the results.

Judging the quality of information

The first pairing was concerned with lecturers and student perceptions about being able to judge the quality of information sources.

\section{Table 4}

There was a divergence of opinion in terms of lecturers confidence in the students' ability to judge the quality of the information sources they would use with nearly $60 \%$ not having confidence in the students' ability to do so whilst over $40 \%$ signified their confidence in the students' judgement. In contrast students were overwhelmingly confident in their ability to judge the quality of the information sources that they would use, with only $9 \%$ of them not being confident. 
Table 6 shows there was a difference in opinion as to the students' perceived awareness of certain library resources and services. A majority of lecturers (60\%) believed that students would be aware of the databases available from the library, but nearly $80 \%$ of lecturers did not have the confidence that the students would know how to use the 'SFX' facility which provides access the full-text of a document where available within MetaLib (the library's federated search engine).

\section{Table 5}

There was some lack of confidence amongst students in the use of library resources. Consistently at least a third of students were not confident in their use of databases, finding usernames and passwords and using SFX. This was despite the fact that final year students were offered and $78 \%$ of them attended training sessions on how to find information for their projects, how to avoid plagiarism by using RefWorks with practical workshops as well as drop-in sessions for specific information seeking problems they may have had.

\section{Evaluating information}

Twenty five lecturers responded to these questions and the majority of them did not express confidence in the students' ability to evaluate the information retrieved, Table 7.

\section{Table 6}

Lecturers expressed a greater degree of faith in terms of recognising bias in an article or website (44\%) than in recognising whether an article is factually correct 
(32\%). Over two thirds of students, however, were confident or very confident in their ability to recognise bias in an article or whether it was factually correct or not.

\section{Citing and referencing}

Data in Table 8 provide a very clear indication that lecturers did not have confidence (92\%) in the students' knowledge of how to use 'RefWorks' to produce a list of references and this was the case for students where $61 \%$ were not confident either.

\section{Table 7}

In terms of knowing how to use a citation style to produce a list of references, opinion was fairly evenly split with $48 \%$ of lecturers not having confidence in the students' ability and 52\% feeling confident or very confident that the students would be able to do so. Students had high levels of confidence about citing books and journals and applying citation styles - over $80 \%$ were either confident or very confident about this.

\section{Searching skills}

As with some of the other responses in this section there was a notable divergence of opinion regarding the ability of students' searching skills as shown in Table 9. Regarding identifying and combining keywords and phrases a majority (56\%) of lecturers had confidence in the students' ability to do so. Similarly, $54 \%$ of lecturers expressed the view that students would be able to search the internet for quality academic information

\section{Table 8}

Students were much more confident in their skills to use search terms and the internet to find the material they needed than lecturers were in students' ability. Well 
over three quarters of students felt they could combine search terms and phrases and use the internet to find what they wanted. Almost half of the students, however, were not confident in their ability to combine terms using Boolean operators.

\section{Discussion}

Quality of the literature review

Both lecturers and students were in broad agreement as to the value and purpose of the literature review, for lecturers this was important to obtain an 'excellent' final year project or dissertation. Similarly students regarded it as an important element of the total work, clearly lecturers had been successful in communicating the importance of the literature review to students. Unfortunately, however, whilst the importance of the literature review may have been accepted by students this did not translate, in the view of lecturers at least, into a large number of good quality literature reviews. Half of the lecturers surveyed could only rate the literature reviews they had seen as either poor or very poor. Looking at the confidence levels expressed by students relating to a broad spectrum of information seeking and handling skills, most clearly felt they had the ability to perform a good literature review. Thus the question arises, why the gap between lecturers' expectations and students' performance?

\section{Sources of information and their location}

There was overall agreement concerning the sources of information that lecturers and students thought they should use when students search for information. There was strong agreement between them in the type of library resources they expected to be used, with the only real divergence in opinion in the use of the internet and the use of their sponsors or industry sources. 
Ercegovac (2009) and Kerins, Madden and Fulton (2004) found similar results in their work where undergraduate students often turned first to an internet search engine to find information. However, it is suspected that students are not sure of the boundaries between what is freely available on the Internet and what is sourced by libraries. Thus, documents appear to be freely available when in fact it is institutional subscriptions behind the scenes that are providing seamless access to expensive resources. This is increasingly likely to be the case as journal publishers open their databases to search engines. Over $90 \%$ of students in the research here expected to use the Internet in their search for information as compared to just under $70 \%$ of lecturers expecting the same. In some very recent work Baer and Li (2009) also reported that over $60 \%$ of undergraduates made Google their first choice and was viewed as meeting their research needs. Ease and accessibility was a key issue for students, as indeed it was for professional engineers. Students, in common with other research findings, also consulted their fellow students, as well as industrial contacts. This was corroborated by our findings.

\section{Database and search engine use}

The main alternative to internet search engines is library-provided databases and resources discovery tools. Whilst $59 \%$ of students said they would use specific library databases (and 96\% electronic journals) the survey showed that a third of students were not confident in knowing what databases the library had to offer and similarly $40 \%$ of lecturers agreed that they thought that students did not know either. It may also be the case that lecturers were not completely confident in their own knowledge of the databases that were available when advising students. 
The persistent use of search engines to find information is noted by Rowlands et al (2008) suggesting that the 'Google generation', (those born after 1993) are most comfortable with accessing and using information via the Internet. Whilst they may be comfortable in the use of computers, Rowlands et al (2008) suggest that young people view, rather than read the material they find on the web, and do not have the analytical skills to assess the information they have found.

This over-familiarity with internet search engines and lack of confidence with library databases may have contributed to past poor literature review performance. Students may perceive that their internet searching is producing good quality literature, but in fact, it is only producing a good quantity of literature - not the same thing.

Indeed, some students in the survey did recognise that there was a possibility of information overload as did a handful of lecturers. In an information society such as ours, where the amount of information available is growing exponentially, the need for excellent evaluation skills is key, and may be lacking amongst students.

Confidence in judging the quality of information

The majority of students in the survey, however, felt confident in their ability to assess the quality of the information they found. Ninety-one per cent of them were confident or very confident in their skills. As mentioned earlier this was not the view shared by the lecturers in the survey who were not confident that the students could judge the quality of the information that they found, nor that they could judge whether there was any bias or that an article was factually correct. This may be a key 
contributing factor to the mismatch between students' overconfidence in their information skills and the poor resulting literature reviews. If students are confident that the information they are finding is of good quality and the lecturers think otherwise, this issue needs to be addressed through training.

\section{Confidence in searching for information}

Students were similarly confident about their ability to use keywords and phrases to find information and to be able to search the Internet. Generally lecturers were much less confident in the ability of their students in this area. The work by Chu and Law (2007) over five meetings with research students suggests that student perceptions of their skills were not borne out by observations, at least initially. The research students they observed used questionable subject searches and used few keyword searches in their information seeking. In fact Chu and Law (2007) found that their engineering research students failed in 8 out of 12 of their subject searches to find anything at all. The research also showed that keyword searches were similarly fairly unsuccessful with 71 out of 91 of the searches conducted finding nothing and the remainder finding too many results to be useful. However, as the students became more experienced in their search strategies they became more successful, migrating from subject searches to simple and then more complex keyword searches. Importantly student perceptions changed over the five meetings as they began to recognise the importance of search strategy techniques. The clear implication being that practice changes perceptions and hence improves search performance and the results obtained. As one lecturer noted in the survey here in a free text response "They [students] need to learn form Part A [their first year] through essays/reports which require them to search, find, read, understand and critically review in a coherent manner". It may be that setting students their first piece of properly 
assessed literature searching work in their final year is too late. They perhaps need to build up their information skills over the course of their study so that by the time they reach their final year, they are fully appraised of what lecturers' expectations are, and have the skills to meet them.

Number of resources searched and sources read

There were also marked differences in terms of the number of resources that lecturers and students thought that students should search during their literature review. Lecturers were clearly more conservative with the majority of them suggesting between 1-10 resources whereas the majority of students thought they would consult either $11-15$ or over 15 resources. Similarly there was some variation in expectations about the number of sources that would be read by students; generally students were a little more conservative as to what they expected to read despite opting to search more resources. This would suggest that there needs to be some level of guidance, whilst not being prescriptive, on the number of resources students might consult, read and cite in a good quality literature review. Again, this may contribute to a better-informed literature review, and go some way to meeting lecturers' performance expectations. In a recent article Warwick et al., (2009) suggest students have a fairly ruthless approach to finding the information they need for their work, carefully judging and measuring in a tactical way the effort required to optimise the results of their work, and sticking very conservatively, to what they knew and hoped worked. The authors suggested that "...academics and system designers should assume lesser motivation, [of students] but greater ingenuity, in students' information seeking than currently may be the case." Warwick et al., (2009, p.2414).

\section{Conclusions}


Clearly the final year Civil and Building students at Loughborough have a greater estimate of their own skills and abilities to retrieve and judge the quality of information than their lecturers think they have. Although we were unable to crosstabulate our findings against a measure of respondents overall ability, a general picture emerges of somewhat overconfident students unable to judge their skills to search effectively in quality databases, with some over reliance on general search engines. However, $43 \%$ of the lecturers did regard the literature reviews they read as being of good quality so in reality many students are succeeding in finding and analysing the literature they needed to support their final year projects.

The research suggests that problems may lie in a lack of awareness of alternatives to internet search engines, and (whatever the resource searched) the ability to use effective search strategies to locate a manageable list of results. Locating the quality information using evaluation skills is also an issue, as was a lack of understanding regarding the number of sources students need to have read to generate a good 'overview' of the literature.

Efficiency in information searching and how to optimise the results obtained by whatever strategy seems to be the style adopted, in part at least, by some students. Thus, any help we can offer that aids students to get good quality results in their search for information whilst optimising their expenditure of effort might prove a successful combination. This is, in fact, little different to the strategy adopted by practising engineers in their search for information. As Fidel and Green (2004) point out, engineers balance a range of factors in their search for information which helps them optimise the results they obtain against the time spent searching for it. 


\section{Recommendations}

This study of lecturer and student perceptions about the literature review associated with the final year projects in the Civil and Building Engineering Department at Loughborough University suggests several recommendations, most of which will likely have application for other programs and universities. Some are based around improving students' search skills and providing opportunities to engage with professional library lecturers and academics in formal and less formal settings where students can freely discuss search strategies. Others relate to setting guidelines and allowing students to understand the proficiency or otherwise of their search skills in order to adopt self-improving strategies.

Guidance from academic lecturers

- Students would benefit from clear guidance and direction from academic lecturers about the types of resources they should be expected to search, particularly the use of databases related to their subject (as alternatives to web sites).

- Students may also benefit from general guidance on the approximate numbers of sources they should be reading and citing.

- Academics might show by reference to good quality examples the literature reviews taken from final year projects where there is evidence of a balanced well structured format with a realistic view of the number, type and citation of references used. 
- Marking schemes should be as detailed as possible, awarding marks for appropriate searching, use and citation of sources.

- Academics should keep abreast of developments within the library (new resources and tools) in order to best advise students.

- Academics and library lecturers should work closely to develop phased interventions on information skills training throughout programmes to coincide with coursework on a progressive basis.

Skills assessment

- Students would benefit from gaining a true picture of their searching skills, perhaps via an online audit type test. This will also allow lecturers to asses training needs.

- Competencies should be measured before and after teaching to ensure learning has taken place.

Content of Library skills training

- Library teaching sessions need to find new ways of increasing students' skill levels with the federated search engine, Metalib, individual databases, bibliographic software package (RefWorks) and direct-linking technology,SFX.

- Specifically, students need training in selecting relevant databases to use, selecting keywords, understanding the differences between Metalib and Google.

- Students need guidance on evaluating information (currency, bias, etc) especially for industry where they may have access to free resources. 
- Students need citation guidance, particularly for non-standard items.

- Students should be provided with information management advice and guidance (e.g. use of bibliographic software packages).

- Provide training and guidance on more effective use of search engines, like advanced searching using Google and Google Scholar.

- Provide teaching on how to use and evaluate hits from Google effectively

\section{Format of Library training}

- Library staff should work with academic lecturers to ensure Information Literacy competencies are built on throughout the degree programmes, to ensure final year project students have the competencies they need to perform a good literature review.

- Organise literature review sessions in conjunction with academic lecturers to ensure they are timely, and get the appropriate "buy-in" from students.

\section{Acknowledgements}

The following contributed to the research, analysis and drafting of this and other reports associated with the project.

Panos Balatsoukas, Elaine Collis, and Susan Manuel

Research funding provided by the UK Centre for Education in the Built Environment, (CEBE), Cardiff University, under project reference: RES6276. 


\section{References}

Baer, W. \& Li, L. 2009. Library and information use patterns by engineering faculty students. <https://smartech.gatech.edu/bitstream/1853/28688/1/EngLibSurvey-BearLi.pdf>. [accessed 19.12.09].

Barker, T., Cook, J. \& Whang, L. (n.d.). Desperately seeking information: where and why engineering students find the information they need.

$<$ <ttp://depts.washington.edu/englib/eld/conf/06/aseeposter06.pdf>, [accessed 17.12.09].

Case, D. 2002. Looking for information: a survey of research on information seeking, needs, and behaviour. San Diego: Academic Press

Chu, S. \& Law, N. 2007. Development of information search expertise: postgraduates' knowledge of searching skills. Portal: Libraries and the Academy, 7(3), 295-316.

Ercegovac, Z. 2009. What engineering sophomores know and would like to know about engineering information sources and access. Issues in Science and Technology Librarianship 57. <http://www.istl.org/09-spring/refereed3.html>, [accessed 12.12.09].

Fidel, R. \& Green, M. 2004. The many faces of accessibility: engineers' perception of information sources. Information Processing and Management. 40(3), 563-581.

Gadd, E., Baldwin, A. \& Norris, M. 2010. The citation behaviour of Civil Engineering students. Journal of Information Literacy. 4(2).

http://ojs.Iboro.ac.uk/ojs/index.php/JIL/index [accessed 7.2.10] 
Hertzum, M. \& Pejtersen. A.M. 2000. The information-seeking practices of engineers: searching for documents as well as people. Information Processing and Management. 36(5), 791-778.

Kerins, G., Madden, R. \& Fulton, C. 2004. Information seeking and students studying for professional careers: the cases of engineering and law students in Ireland. Information Research, 10(1), http://InformationR.net/ir/10-1/paper208.html [accessed 10.12.09]

Kwasitsu, L. 2003. Information seeking behavior of design, process and manufacturing engineers. Library and Information Science Research 25(4), 459-476.

Rowlands, I., Nicholas, D., Williams, P., Huntington P., Fieldhouse, M., Gunter, B., Withey. R., Jamali, H., Dobrowolski T. \& Tenopir, C. 2008. The Google generation: the information behaviour of the researcher of the future. Aslib Proceedings 60(4), 290-310.

Tenopir, C. \& King D.W. 204. Communication patterns of engineers. Wiley: New York.

Warwick, C., Rimmer, J., Blandford, A., Gow, J. \& Buchanan, G. Cognitive economy and satisficing in information seeking: A longitudinal study of undergraduate information behaviour. Journal of the American Society for Information Science and Technology, 60(12), 2402-2415.

Wilson T. 1999. Models in information behaviour research. Journal of Documentation. 55(3), 249-270 


\section{Tables}

Table 1 Quality of literature reviews

\begin{tabular}{|l|c|c|c|c|c|}
\hline Response & No opinion & Excellent & Good & Poor & Very poor \\
\hline Number & 4 & 0 & 12 & 10 & 2 \\
\hline Percentage & 14 & 0 & 43 & 36 & 7 \\
\hline
\end{tabular}

Table 2. Problems that lecturers thought students may have in their search for information

\begin{tabular}{|l|c|c|}
\hline Problem Anticipated & Responses & Percentage \\
\hline Finding relevant information (including which sources to use) & 7 & $25 \%$ \\
\hline Poor search strategy & 6 & $21 \%$ \\
\hline How to analyse information and determine relevancy & 5 & $18 \%$ \\
\hline Poor motivation/inadequate appreciation of the importance of the & 4 & $14 \%$ \\
\hline literature review & & \\
\hline Lack of initial guidance & 3 & $10 \%$ \\
\hline Inadequate knowledge of how to use utilise databases & 3 & $10 \%$ \\
\hline Information overload & 3 & $10 \%$ \\
\hline Inaccessibility of some resources & 2 & $7 \%$ \\
\hline Time management & 2 & $7 \%$ \\
\hline
\end{tabular}


Table 3. Problems anticipated by students

\begin{tabular}{|l|c|c|}
\hline Problem Anticipated & Responses & Percentage \\
\hline Finding specific information (source or type) & 18 & $33 \%$ \\
\hline Finding relevant information & 7 & $13 \%$ \\
\hline Dealing with information overload & 6 & $11 \%$ \\
\hline Locating the full-text of relevant material & 5 & $9 \%$ \\
\hline Finding current information & 3 & $6 \%$ \\
\hline Using databases & 2 & $4 \%$ \\
\hline Having the right study skills (time mgt, reading, writing) & 2 & $4 \%$ \\
\hline Collecting primary data & 1 & $2 \%$ \\
\hline
\end{tabular}

Table 4. Perceived confidence in students' ability to judge the quality of information

Lecturer: How confident are you that your students are able to the judge quality of the

information sources that they will use

Student: How confident are you about judging the quality of the information sources that you use

Not confident

Confident

Very confident

\begin{tabular}{|lccc|}
\hline Lecturers & 57 & 43 & 0 \\
\hline Students & 9 & 80 & 11 \\
\hline
\end{tabular}


Table 5. Perceived confidence in students' knowledge and skills in using library resources (percent)

Lecturer: How confident are you that your students know what databases the library has to offer Student: How confident are you about what databases the library has to offer

\begin{tabular}{|lccc|} 
& Not confident & Confident & Very confident \\
\hline Lecturers & 40 & 60 & 0 \\
\hline Students & 33 & 63 & 4
\end{tabular}

Lecturer: How confident are you that your students know how to find usernames and passwords for different databases or e-journals

Student: How confident are you about finding usernames and passwords for different databases or e-journals

\begin{tabular}{|c|c|c|c|}
\hline & Not confident & Confident & Very confident \\
\hline Lecturers & 52 & 48 & 0 \\
\hline Students & 37 & 48 & 15 \\
\hline
\end{tabular}

Student: How confident are you about using 'SFX' to locate full-text of articles

\begin{tabular}{|lccc|} 
& Not confident & Confident & Very confident \\
\hline Lecturers & 78 & 22 & 0 \\
\hline Students & 48 & 39 & 13 \\
\hline
\end{tabular}


Table 6. Perceived confidence in students' ability to evaluate the quality of information sources (percent)

Lecturer: How confident are you that your students will be able to recognise bias in an article or website

Student: How confident are you about recognising bias in an article or website

\begin{tabular}{|c|c|c|c|}
\hline & Not confident & Confident & Very confident \\
\hline Lecturers & 56 & 44 & 0 \\
\hline Students & 20 & 57 & 22 \\
\hline \multicolumn{4}{|c|}{ Lecturer: How confident are you that your students will be able to recognise whether an arti } \\
\hline \multicolumn{4}{|c|}{ Student: How confident are you about recognising whether an article is factually correc } \\
\hline & Not confident & Confident & Very confident \\
\hline Lecturers & 68 & 32 & 0 \\
\hline Students & 31 & 57 & 11 \\
\hline
\end{tabular}

Table 7. Perceived confidence in students' ability to correctly use referencing tools and citing practice (percent)

Lecturer: How confident are you that your students know how to use 'RefWorks' to produce lists of references

Student: How confident are you about using 'RefWorks' to produce lists of references

\begin{tabular}{|lccc|} 
& Not confident & Confident & Very confident \\
\hline Lecturers & 92 & 8 & 0 \\
\hline Students & 61 & 30 & 9
\end{tabular}

Lecturer: How confident are you that your students know how to use a citation style to produce a 
list of references

Student: How confident are you about using a citation style to produce a list of references

\begin{tabular}{|lccc|} 
& Not confident & Confident & Very confident \\
\hline Lecturers & 48 & 48 & 4 \\
\hline Students & 19 & 56 & 26 \\
\hline
\end{tabular}

Table 8. Perceived confidence in students' ability to use search terms to find information sources (percent)

Lecturer: How confident are you that your students will be able to identify and combine suitable keywords and phrases to pinpoint relevant information

Student: How confident are you about choosing and combining suitable keywords and phrases to pinpoint relevant information

\begin{tabular}{|lccc|} 
& Not confident & Confident & Very confident \\
\hline Lecturers & 44 & 56 & 0 \\
\hline Students & 4 & 67 & 30
\end{tabular}

Lecturer: How confident are you that your students will be able to search the internet for quality academic information

Student: How confident are you about searching the internet for quality academic information

\begin{tabular}{|c|c|c|c|}
\hline & Not confident & Confident & Very confident \\
\hline Lecturers & 42 & 54 & 4 \\
\hline Students & 13 & 56 & 31 \\
\hline \multicolumn{4}{|c|}{ Lecturer: How confident are you that your students will be able to combine keywords using } \\
\hline \multicolumn{4}{|c|}{ Boolean operators (AND, OR and NOT) } \\
\hline \multicolumn{4}{|c|}{ Student: How confident are you about combining keywords using Boolean operators (AND, OR } \\
\hline
\end{tabular}


and NOT)

Not confident

Confident

Very confident

Lecturers

78

28

0

Students

46

43

11 